ISSN: $2354-1431$

http://tckh.daihoctantrao.edu.vn/

\title{
Quy trình tổ chức sinh hoạt chuyên môn theo định hướng dạy học tích hợp liên môn
}

Hà Mỹ Hạnh ${ }^{a, *}$

a Trưòng Đại học Tân Trào

*Email:hamyhanhedu@gmail.com

\section{Article info}

Recieved:

05/7/2017

Accepted:

$03 / 8 / 2017$

\section{Keywords:}

Quality of services;

Student's satisfaction;

Tan Trao university.

\begin{abstract}
This article presents studied results of the connection between quality of training services and student's satisfaction at TTU. The result based on questionnaires from 396 students with 26 questions regarding 5 factors affecting quality of training services (reliability, applicable potential, service capacity, sympathy, facilities) and student's satisfaction. The study shows that sympathy and service capacity most impact on student's satisfaction.
\end{abstract}

\section{I. Đặt vấn đề}

Thực hiện đề án "Đổi mói căn bản, toàn diện giáo dục và đào tạo" theo Nghị quyết Đại hội toàn quốc lần thứ XI của Đảng và Nghị quyết Hội nghị lần thứ 8 Ban Chấp hành Trung ương khóa XI, giáo dục phổ thông đang có nhiều đổi mới, đặc biệt sinh hoạt chuyên môn theo hướng dạy học tích hợp liên môn là một trong những hoạt động trọng tâm, được Bộ Giáo dục và Đào tạo chỉ đạo triển khai nhằm nâng cao hiệu quả giảng dạy và giáo dục học sinh ở các trường phổ thông.

Sinh hoạt chuyên môn (SHCM) là nhân tố quyết định trực tiếp đến chất lượng dạy học của các trường phổ thông hiện nay. Tuy nhiên, hoạt động này ở các trường phổ thông còn nhiều bất cập, mang tính hình thức, chưa phát huy được hết vai trò vốn có của SHCM. Do đó, quản lí SHCM là nhiệm vụ hàng đầu, trọng tâm trong quá trình quản lí của các trường phổ thông. Bài viết đề cập tới một vấn đề cơ bản quản lý sinh hoạt chuyên môn theo hướng dạy học tích hợp liên môn ở các trường phổ thông

II. Quy trình tổ chức sinh hoạt chuyên môn theo định hướng dạy học tích hợp liên môn

\section{Sinh hoạt chuyên môn theo định hướng dạy học tích hợp liên môn}

SHCM theo định hướng dạy học tích hợp liên môn (THLM) có thể hiểu là hoạt động bồi dưỡng chuyên môn, nghiệp vụ cho giáo viên được tổ chức theo định kỳ, ở đó giáo viên trao đổi tháo gỡ những khó khăn trong việc lồng ghép, xử lý nội dung kiến thức của nhiều môn học có liên quan để phát triển năng lực cho học sinh nhằm nâng cao chất lượng dạy và học.

2. Quy trình tổ chức sinh hoạt chuyên môn theo định hướng dạy học tích hợp liên môn

\subsection{Mục tiêu của quy trình}

+ Quy trình tổ chức sinh hoạt chuyên môn theo định hướng dạy học tích hợp liên môn được xây dựng cụ thể thành các bước giúp giáo viên và học sinh thực hiện một cách thuận lợi.

+ Thực hiện tốt các bước trong quy trình vừa đạt được mục tiêu phát triển năng lực cho học sinh vừa đạt các mục tiêu khác trong chương trình đào tạo.

\subsection{Nội dung và cách thức tiến hành}

\section{Bước 1: Chọn chủ đề dạy học THLM}

Chủ đề tích hợp liên môn là những chủ đề có nội dung kiến thức liên quan đến hai hay nhiều môn học, thể hiện ở sự ứng dụng của chúng trong cùng một hiện tượng, quá trình trong tự nhiên hay xã hội. Ví dụ: Kiến thức Vật lí và Công nghệ trong động cơ, máy phát điện; kiến thức Vật lí và Hóa học trong nguồn điện hóa học; kiến thức Lịch sử và Địa lí trong chủ quyền biển, đảo; kiến thức Ngữ văn và Giáo dục Công dân trong giáo dục đạo đức, lối sống...

Lựa chọn chủ đề tích hợp liên môn là khâu đầu tiên, là cơ sở cho quá trình dạy học THLM. Các chủ đề tích hợp liên môn có tính thực tiễn nên sinh động, hấp dẫn đối với 
học sinh, có ưu thế trong việc tạo ra động cơ, hứng thú học tập cho học sinh. Học các chủ đề tích hợp, liên môn, học sinh được tăng cường vận dụng kiến thức tổng hợp vào giải quyết các tình huống thực tiễn, ít phải ghi nhớ kiến thức một cách máy móc, nhờ đó năng lực và phẩm chất của học sinh được hình thành và phát triển. Ngoài ra, dạy học các chủ đề tích hợp, liên môn giúp cho học sinh không phải học lại nhiều lần cùng một nội dung kiến thức ở các môn học khác nhau, vừa gây quá tải, nhàm chán, vừa không có được sự hiểu biết tổng quát cũng như khả năng ứng dụng của kiến thức tổng hợp vào thực tiễn.

Thay cho việc dạy học đang được thực hiện theo từng bài/tiết trong sách giáo khoa như hiện nay, các tổ/nhóm chuyên môn căn cứ vào chương trình và sách giáo khoa hiện hành, lựa chọn nội dung để xây dựng các chủ đề dạy học trong mỗi môn học và các chủ đề tích hợp liên môn phù hợp với việc sử dụng phương pháp dạy học tích cực trong điều kiện thực tế của nhà trường. Trên cơ sở rà soát chuẩn kiến thức, kĩ năng, thái độ theo chương trình hiện hành và các hoạt động học dự kiến sẽ tổ chức cho học sinh theo phương pháp dạy học tích cực, xác định các năng lực và phẩm chất có thể hình thành cho học sinh trong mỗi chuyên đề đã xây dựng.

Các kiến thức liên môn có thể nằm ở chương trình của các lớp khác nhau và đều có thể được lựa chọn để xây dựng thành các chủ đề dạy học tích hợp liên môn. Tùy vào điều kiện, hoàn cảnh cụ thể của từng trường có thể xây dựng các chủ đề tích hợp liên môn phù hợp. Trong thời gian đầu, để tránh sự xáo trộn nhiều gây khó khăn cho việc thực hiện kế hoạch giáo dục chung, nhà trường có thể chọn các nội dung kiến thức liên môn nằm trong chương trình của một lớp để xây dựng chủ đề dạy học tích hợp liên môn, đảm bảo hoàn thành chương trình môn học của khối đó trong năm học. Trong những năm học tiếp theo, trên cơ sở các chủ đề tích hợp liên môn đã được xây dựng và thực hiện, nhà trường tiếp tục mở rộng xây dựng các chủ đề tích hợp liên môn trong toàn bộ kế hoạch giáo dục nhà trường.

Việc chọn các chủ đề dạy học tích hợp liên môn có thể giao cho các tổ/nhóm chuyên môn xây dựng và thực hiện một vài chủ đề tích hợp liên môn phù hợp.

\section{Bước 2: Chọn nội dung trong chuơng trình các môn học đự̆c tích họp trong chủ đề}

Việc lựa chọn nội dung trong chương trình các môn học được tích hợp trên cơ sở các chủ đề đã được lựa chọn. Việc lựa chọn nội dung cần đảm bảo các yêu cầu sau:

- Các nội dung kiến thức thuộc chương trình các môn học được dạy học tích hợp trong chủ đề; nêu rõ yêu cầu cần đạt; tên bài (tiết), thời lượng phân phối chương trình hiện hành và thời điểm dạy học theo chương trình hiện hành;

- Phương án/kế hoạch dạy học môn học sau khi đã tách riêng phần nội dung kiến thức được dạy học theo chủ đề đã xây dựng;

- Trình bày nội dung dạy học trong chủ đề; phân tích về thời lượng và thời điểm thực hiện chủ đề trong mối liên hệ phù hợp với chương trình dạy học các môn học liên quan;

- Trình bày ý tưởng/câu hỏi của chủ đề nhằm giải quyết một vấn đề nào đó để qua đó học sinh học được nội dung kiến thức liên môn và các kĩ năng tương ứng đã được tách ra từ chương trình các môn học nói trên, có thể là vấn đề theo nội dung dạy học hoặc vấn đề cần giải quyết trong thực tiễn;

- Ý nghĩa của việc thực hiện chủ đề trong dạy học các môn học liên quan/hoạt động trải nghiệm sáng tạo đối với việc hình thành kiến thức, kĩ năng, thái độ và phát triển năng lực, phẩm chất của học sinh.

\section{Bước 3: Chuẩn bị bài dạy minh họa}

- Giáo viên dạy minh họa chuẩn bị bài dạy, tổ chuyên môn tổ chức họp thảo luận lấy ý kiến góp ý từ các giáo viên trong tổ chuyên môn để cùng nhau thiết kế, trao đổi, đầu tư thời gian để chuẩn bị bài học THLM. Bài dạy minh họa nên lựa chọn từ các môn học phù hợp cho việc áp dụng các phương pháp, kỹ thuật dạy học tích cực hoặc các phương pháp, kỹ thuật dạy học mới được tập huấn để giáo viên thử nghiệm các sáng kiến kinh nghiệm mới, cách dạy mới...

- Bài dạy minh họa cần được thể hiện linh hoạt, sáng tạo. Giáo viên lựa chọn nội dung, phương pháp, kỹ thuật dạy học để đạt được mục tiêu/chuẩn kiến thức kĩ năng của từng môn học, không phụ thuộc quá nhiều vào nội dung trong sách giáo khoa, các quy trình, các bước dạy trong sách giáo viên, mà dựa vào kinh nghiệm và vốn kiến thức của học sinh, giáo viên có thể lựa chọn các ví dụ và ngữ liệu gần gũi với các em để đạt được mục tiêu của bài học.

\section{Bước 4: Tổ chức dạy minh họa - dụ giờ dạy học THLM}

Tổ chức dạy minh họa - dự giờ là khâu quan trọng nhất trong sinh hoạt chuyên môn.

\section{* Dạy minh họa}

- Giáo viên cần tiến hành dạy minh họa trên học sinh của lớp mình. Yêu cầu không được luyện tập trước khi dạy minh họa. 
- Chuẩn bị không gian, bàn ghế thuận tiện cho người dự dễ dàng quan sát các hoạt động học tập của học sinh.

- Các hoạt động thiết kế đảm bảo thời lượng một tiết dạy minh họa không nên kéo dài quá so với quy định của 1 tiết học.

\section{* Dụ giò}

- Ban giám hiệu và các giáo viên trong trường cùng dự giờ.

- Dự giờ minh họa đòi hỏi sự tập trung cao độ của các giáo viên. Lựa chọn vị trí quan sát để nắm bắt được thông tin chính xác về việc học của học sinh, thấy được nét mặt, hành động, thao tác, sản phẩm của học sinh.

- Người dự giờ cần vẽ sơ đồ chỗ ngồi, quan sát, nghe, nhìn, suy nghĩ và ghi chép diễn biến hoạt động học của học sinh trong giờ học hay những biểu hiện tâm lý của HS.

- Người dự có thể chụp ảnh hoặc quay phim các hoạt động học của học sinh trong các tình huống nhưng không làm ảnh hưởng đến giờ học.

- Quan sát ghi chú các hoạt động học của học sinh, thái độ, cử chỉ, sự tham gia hay không tham gia của học sinh vào nội dung bài học. Tập trung quan sát những biểu hiện qua nét mặt, thái độ, hành vi, mối quan hệ tương tác giữa $\mathrm{HS}$ - GV, HS - HS.

- Việc dự giờ và quan sát học sinh thường xuyên sẽ giúp cho mỗi giáo viên tự suy nghĩ, phát hiện và hiểu rõ nguyên nhân của những khó khăn mà học sinh đang gặp phải trong quá trình học tập. Từ đó tự điều chỉnh cách dạy của mình cho phù hợp với đối tượng học và có kế hoạch quan tâm giúp đỡ những học sinh đang gặp khó khăn về nhận thức hoặc hoàn cảnh gia đình....

Bước 5: Thảo luận về giờ học, tổ chức kiểm tra đánh giá SHTCM theo dịnh hướng dạy học THLM

Trong khi thảo luận vai trò của người chủ trì hết sức quan trọng. Người chủ trì không chỉ có khả năng chuyên môn mà còn có năng lực tổ chức, nhanh, nhạy, linh hoạt xử lí các tình huống để điều hành, dẫn dắt buổi sinh hoạt chuyên môn đi đúng hướng, đúng trọng tâm, đạt hiệu quả và tạo được bầu không khí thân thiện, cởi mở, gắn bó giữa các thành viên trong nhà trường.

\section{* Địa điểm thảo luận}

Địa điểm thảo luận cần đủ rộng, đủ chỗ ngồi cho người tham dự. Nếu có các phương tiện hỗ trợ như máy tính, máy chiếu, projector thì càng tốt... cần sắp xếp bàn ghế để người tham dự ngồi đối diện với nhau, tạo điều kiện dễ dàng cho việc trao đổi ý kiến đồng thời làm cho bầu không khí thảo luận thân thiện, gần gũi.

\section{* Tiến trình buổi thảo luận}

- Bước 1: Người chủ trì nêu mục đích của buổi thảo luận.

- Bước 2: Giáo viên dạy minh họa đại diện cho nhóm thiết kế nêu mục tiêu cần đạt của bài học, những ý tưởng thay đổi về nội dung, phương pháp, đồ dùng dạy học để phù hợp với đối tượng học sinh cụ thể và cảm nhận sau khi dạy bài học, sự hài lòng, những băn khoăn hay khó khăn khi thực hiện bài dạy.

- Bước 3: Giáo viên dự giờ chia sẻ ý kiến về giờ học.

+ Các giáo viên tham dự có thể đặt câu hỏi để hiểu rõ hơn ý đồ của người dạy. Nếu thực hiện chụp ảnh hay quay video giờ học, người chủ trì có thể cho giáo viên xem lại hình ảnh các hoạt động trọng tâm hoặc dừng lại ở một số hình ảnh HS.

+ Khuyến khích tất cả các giáo viên dự giờ chia sẻ những quan sát, suy nghĩ, cảm nhận của mình về giờ học, những thông tin thu được trong quá trình quan sát.

+ Mỗi giáo viên khi bắt đầu phát biểu nên phát biểu về những điều tốt mình học được từ đồng nghiệp trong giờ dạy, sau đó mới đưa ra ý kiến cần trao đổi, như vậy sẽ tạo được sự tự tin hơn cho đồng nghiệp.

+ Để đảm bảo không khí buổi sinh hoạt chuyên môn thân thiện, cởi mở người chủ trì cần lắng nghe tích cực và khéo léo hướng buổi thảo luận đi đúng trọng tâm, tập trung vào phân tích hoạt động học tập của học sinh để đạt được mục đích, không nên để người dự mổ xẻ, phân tích, xoi mói những hạn chế của giáo viên dạy minh họa..

+ Người góp ý cần căn cứ vào mục tiêu của bài học để hiến kế đưa ra các giải pháp để giúp người dạy khắc phục những hạn chế sao cho tạo cơ hội cho tất cả các học sinh đều được tham gia học tập, tiếp thu kiến thức một cách hiệu quả.

+ Mỗi người dự giờ tự tìm ra những yếu tố tích cực, suy nghĩ xem mình đã học được gì từ bài học này trước khi đưa ra những nhận xét về những hạn chế của giờ học.

+ Không áp đặt ý kiến, kinh nghiệm chủ quan cá nhân, quá chú trọng đến các quy trình truyền thống của một giờ dạy. Người dự chia sẻ những khó khăn và những kết quả của giờ học. Đặc biệt là không đánh giá giáo viên, không xếp loại giờ học và không kết luận cần phải thay đổi theo cách nào. Trong quá trình thảo luận các giáo viên sẽ đưa ra rất nhiều giải pháp khác nhau, tuy nhiên mỗi giáo viên sẽ tự suy nghĩ và lựa chọn giải pháp phù hợp với học sinh và điều kiện học tập của lớp mình. 
+ Nếu cần thiết, các giáo viên có thể cùng thảo luận thiết kế lại bài học dựa trên thực tế và những kinh nghiệm, biện pháp được rút ra trong bài học minh họa để kiểm chứng cho những giải pháp đã đưa ra.

+ Cần lưu ý rằng SHTCM theo định hướng dạy học THLM không nhất thiết chỉ dành cho một tổ chuyên môn. Giáo viên thuộc các tổ chuyên môn khác nhau có thể học tập được rất nhiều từ đồng nghiệp ở tổ chuyên môn khác.

+ Có kế hoạch kiểm tra đánh giá quá trình và kết quả dạy của giáo viên, học tập của HS; thảo luận và biên soạn các phiếu đánh giá GV, HS theo nội dung bài học.

Thông qua dạy học THLM, thảo luận thống nhất những nội dung cần điều chỉnh, làm cho nội dung các bài học trong sách giáo khoa, tài liệu học được cập nhật, phù hợp với đặc điểm của $\mathrm{HS}$ và với thực tiễn dạy học của nhà trường.

Trao đổi thống nhất mục đích yêu cầu từng bài dạy, những kiến thức cơ bản, phương pháp dạy học, sử dụng đồ dùng phương tiện dạy học, cách tổ chức lớp học để giúp HS lĩnh hội kiến thức mới nhanh nhất, có hiệu quả nhất.

* Định huoóng phân tích bài học tích hợp liên môn

Các phương pháp và kĩ thuật dạy học tích cực nói chung đều nhằm tổ chức hoạt động học tích cực, tự lực, sáng tạo của học sinh. Quá trình dạy học mỗi chủ đề được thiết kế thành các hoạt động học của học sinh dưới dạng các nhiệm vụ học tập kế tiếp nhau. Học sinh tích cực, chủ động và sáng tạo trong việc thực hiện các nhiệm vụ học tập dưới sự hướng dẫn của GV. Phân tích giờ dạy theo quan điểm đó là phân tích hiệu quả hoạt động học của học sinh, đồng thời đánh giá việc tổ chức, kiểm tra, định hướng hoạt động học cho học sinh của GV.

Buớc 6: Ap dụng bài học kinh nghiệm vào thục tiễn dạy học hàng ngày

Sau khi thảo luận về tiết dạy đầu tiên, tất cả GV cùng suy ngẫm có hay không tiếp tục thực hiện quá trình dạy học THLM. Nếu bài học vẫn chưa hoàn thiện thì cần tiếp tục nghiên cứu để tiến hành dạy ở các lớp sau cho hoàn thiện hơn. Các GV cùng thảo luận thiết kế lại bài học dựa trên thực tế và những kinh nghiệm, biện pháp được rút ra trong bài học minh họa để kiểm chứng cho những giải pháp đã đưa ra.

GV viết bài báo cáo về những gì học được liên quan đến chủ đề nghiên cứu và mục tiêu của họ trong giảng dạy. Thông qua những buổi SHCM theo định hướng dạy học THLM, GV sẽ áp dụng những kinh nghiệm tích lũy được vào bài học hàng ngày để đảm bảo cơ hội học tập hiệu quả, đồng đều cho HS trong lớp dạy.

\section{TÀI LIỆU THAM KHẢO}

1. Bộ Giáo dục và Đào tạo (2014), Sinh hoạt chuyên môn, Nxb Đại học Sư Phạm;

2. Bộ Giáo dục và Đào tạo (2015), Tài liệu tập huấn dạy học tích hợp liên môn, Hà Nội;

3. Đỗ Hương Trà (chủ biên) (2015), Dạy học tích hợp phát triển năng lục HS - Quyển 1, Nxb Đại học Sư Phạm. 